Gut, 1971, 12, 789-793

\title{
Incidence of small-intestinal mucosal abnormalities and of clinical coeliac disease in the relatives of children with coeliac disease
}

\author{
D. C. ROBINSON, A. J. WATSON, E. H. WYATT, J. M. MARKS, AND \\ D. F. ROBERTS
}

From the University Departments of Child Health, Pathology, Dermatology, and the Laboratory of Human Genetics, Newcastle upon Tyne

SUMMARY Evidence is presented of a higher than normal incidence both of clinical coeliac disease and of small-intestinal mucosal abnormalities in relatives of children with coeliac disease. In such relatives the incidence of mucosal abnormality may differ from the incidence of clinical coeliac disease. The data show an absence of any simple Mendelian pattern of inheritance: in place of the hypothesis that inheritance is through a dominant gene of reduced penetrance, it is argued that the pathogenesis of coeliac disease is multifactorial, the genetic basis of susceptibility being polygenic and interacting with environmental factors. On this hypothesis the relative contributions of inheritance and environment to liability to the clinical condition are estimated, the genetic component being $45 \% \pm 9$. Environmental factors appear more important in the development of mucosal abnormality.

It is well established that coeliac disease is more likely to occur in the relatives of known cases (Thaysen, 1935; Thompson, 1951; Carter, Sheldon, and Walker, 1959; MacDonald, Dobbins, and Rubin, 1965; Stewart, Pollock, Hoff brand, Mollin, and Booth, 1967; McCrea, 1969) but there is room for further studies using rather stricter diagnostic criteria than some of the earlier workers used. Also we considered it important to investigate, by means of peroral biopsy, the incidence of small-intestinal mucosal abnormalities in members of susceptible families. To this end we instituted a systematic study of such biopsy specimens obtained from the parents of children with proven coeliac disease. At the same time we conducted a searching review of the medical histories of the parents and other relatives. Although it would obviously have been valuable to biopsy siblings as well as parents we regarded this as unjustifiable without some particular clinical indication.

\section{Subjects and Mcthods}

The propositi were children who had first presented with clinically overt coeliac disease and malabsorption. None of the children was more than 7 years of age at the time of presentation and most were conReceived for publication 7 July 1971 . siderably younger. In all instances the diagnosis had been supported by the findings on peroral biopsy of the duodenum or upper jejunum, and confirmed by clinical response to gluten withdrawal. The families chosen for investigation were those of a consecutive but otherwise random series of 22 coeliac children attending hospital for routine follow up. In 19 of these 22 children the mucosal biopsy specimens appeared flat on stereomicroscopy and one showed an atrophic convoluted appearance with a mosaic pattern. Histological examination of these 20 specimens showed subtotal villous atrophy and characteristic changes in the surface epithelial cells (enterocytes). The remaining two biopsy specimens showed a convoluted pattern and the histological features of partial villous atrophy, but both children had been on a gluten-free diet and were in clinical remission.

The parents of those 22 children were invited to help in the investigation. One father was dead and in two instances the parents had separated and the father was not accessible. All 41 available parents were interviewed at home and a full family history was obtained. Whenever there were symptoms suggestive of dyspepsia or of small-intestinal disorder in any relative, additional information was sought by clinical examination, by discussion with the 
family doctor, and by inspection of hospital records. Thirty of the 41 parents agreed to undergo smallintestinal biopsy.

The mucosal biopsy specimen was taken, with a Crosby capsule, from the duodenum or the first $50 \mathrm{~cm}$ of jejunum after a radiological check on the position of the capsule. The specimen was handled in the usual manner (Shuster, Watson, and Marks, 1967), examined under a stereomicroscope, photographed, and a part taken for histological examination of paraffin sections.

\section{Classification of Mucosal Appearances}

The stereomicroscopic appearances are classified as follows:

FLAT

There is a complete absence of villi or of mucosal ridges; crypt orifices are fully visible; the surface may show a mosaic pattern caused by a network of grooves.

\section{CONVOLUTED}

The predominant feature consists of convoluted ridges; a convolution is arbitrarily defined as an angulated mucosal ridge in which there are at least two angles not exceeding $90^{\circ}$. Atrophic forms occur on which a mosaic pattern may be superimposed.

NORMAL

A variety of other appearances are considered normal; these include finger and leaf-shaped villi, broad leaves, and joined leaves (ridges) which may be obtusely angulated or show a single acute angle.

HISTOLOGICAL ABNORMALTIES

Significant histological abnormalities are considered to comprise partial or subtotal atrophy of villi accompanied by elongation, and in some instances by branching of the mucosal crypts; an increased number of crypt cells in mitosis; atrophy and pseudostratification of the surface cells (enterocytes) sometimes accompanied by loss of goblet cells; increased density of chronic inflammatory cells (lymphocytes, plasma cells, eosinophils, histiocytes) in the lamina propria. The conventional term for the most advanced changes is 'subtotal villous atrophy' and for lesser degrees of abnormality 'partial villous atrophy'; both terms should imply retrogressive changes in enterocytes.

\section{Results}

Clinical histories, sufficiently detailed for analysis, were obtained in respect of 68 first degree relatives
(34 parents and 34 sibs), 164 second degree relatives (81 male, 83 female), and 238 third degree relatives (114 male, 124 female). Two of the first degree relatives (one parent, one sib) gave histories which were regarded as indicative of coeliac disease (Table). Seven of the second and third degree relatives reported past gastrointestinal symptoms, but on further enquiry these could all be identified as due to gallbladder disease, peptic ulceration, or hiatus hernia.

\begin{tabular}{|c|c|c|c|c|c|c|c|c|c|}
\hline \multirow[t]{2}{*}{ Relation } & \multicolumn{3}{|c|}{ Number } & \multicolumn{3}{|c|}{ Positive History } & \multicolumn{3}{|c|}{$\begin{array}{l}\text { Mucosal } \\
\text { Abnormality }\end{array}$} \\
\hline & $\sigma^{*}$ & $q$ & Total & के & q & Total & o & q & Total \\
\hline \multirow{4}{*}{$\begin{array}{l}\text { Sibs } \\
\text { (first degree) } \\
\text { Parents } \\
\text { (first degree) } \\
\text { Uncles/aunts etc } \\
\text { (second degree) } \\
\text { First cousins etc } \\
\text { (third degree) }\end{array}$} & 14 & 20 & 34 & 0 & 1 & 1 & - & - & - \\
\hline & $c_{c}^{17}$ & 17 & 34 & 1 & o & 1 & 2 & 1 & 3 \\
\hline & 81 & 83 & 164 & 0 & 0 & 0 & - & & - \\
\hline & 114 & 124 & 238 & 0 & 0 & 0 & - & - & - \\
\hline
\end{tabular}

Table Incidence of coeliac disease and of mucosal abnormalities in relatives of 22 randomly selected coeliac children ${ }^{1}$

1 Of three parents with abnormal mucosa only one (a father) also had a positive history.

'Total of 16 mothers and 13 fathers biopsied.

Biopsy specimens of small-intestinal mucosa were obtained from 29 parents $(16$ mothers and 13 fathers) of 17 propositi. One of the mothers had a mucosal biopsy which was partly flat and partly convoluted with corresponding histological changes of subtotal and partial villous atrophy in adjacent areas (Fig. 1). She suffered from thyrotoxicosis which was partially controlled by carbimazole at the time of biopsy, but gave no history of gastrointestinal symptoms - not even the intestinal hurry commonly associated with thyrotoxicosis. Her blood haemoglobin and serum levels of iron, folate, vitamin $\mathbf{B}_{12}$, calcium, phosphate, and alkaline phosphatase were all normal. She has not been investigated for steatorrhoea. Despite the biopsy findings we regard her as not suffering from clinical coeliac disease. The father from another family had a mucosal biopsy which was $50 \%$ convoluted (Fig. 2), and showed features of partial villous atrophy without much abnormality of the enterocytes. He gave a history of 'rickets' in childhood, was of short stature $(158 \mathrm{~cm})$, and showed mild finger clubbing. Taking all these findings together we are inclined to regard him as a case of coeliac disease in an inactive phase with partial recovery of the mucosa. Another father showed a convoluted mucosa with histological changes of partial villous atrophy, although unaccompanied by any obvious abnormality of the 


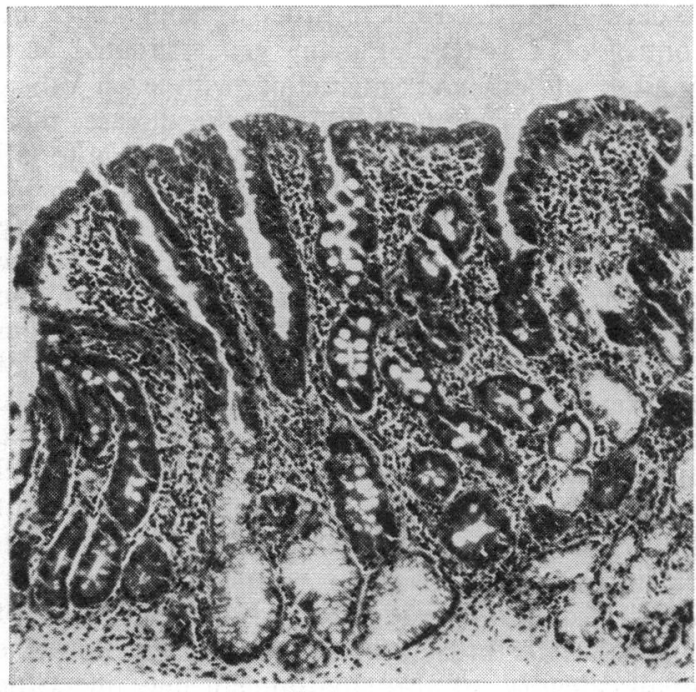

Fig. 1a

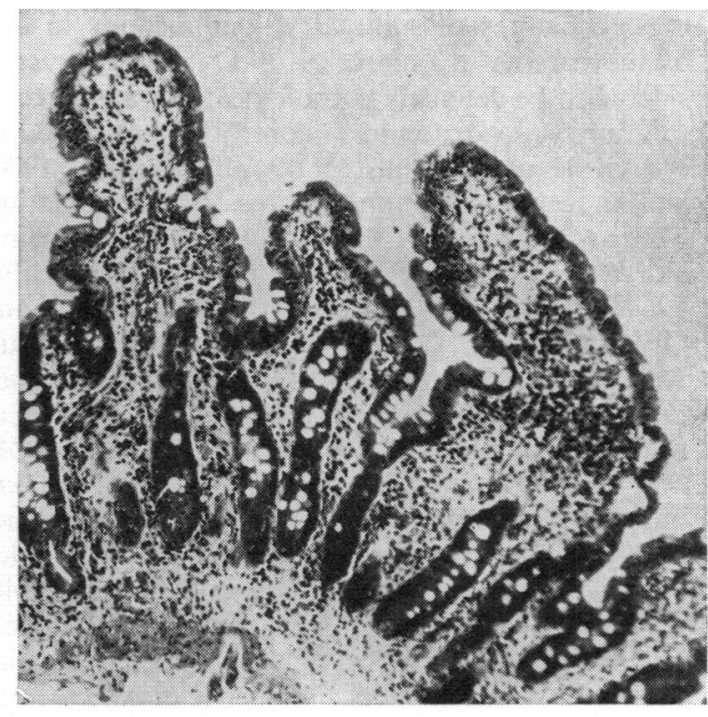

Fig. 1b

Fig. 1 Jejunal mucosa from mother of coeliac child: (a) area showing subtotal villous atrophy, and (b) adjacent area showing partial villous atrophy. Haematoxylin and eosin. $\times 185$.

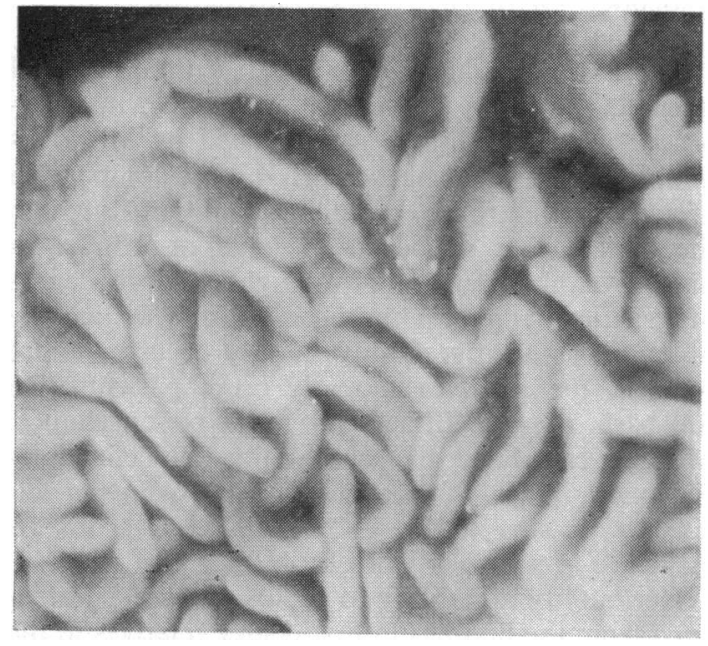

Fig. 2 Jejunal mucosa from father of coeliac child. Surface view showing convolutions. $\times 25$.

enterocytes. Although he had his bowels open three times daily he denied any other gastrointestinal symptoms and we consider that he is not a case of overt coeliac disease. Of the 34 siblings only one, a sister, was diagnosed as having clinical coeliac disease on the basis of her history of failure to thrive, characteristic clinical appearance, steatorrhoea, and a favourable response to gluten with- drawal. Small-intestinal biopsy had not been performed.

\section{Discussion}

\section{CLINICAL FINDINGS}

The history of coeliac disease in one of the 34 siblings and in one of the 34 parents is considerably above the estimated population incidence of 1 in 1,850 (McCrae, 1969), and is in keeping with the findings of previous workers that there is an increased familial incidence of the disease. In his recent study of 100 children with coeliac disease, all confirmed by intestinal biopsy, McCrae (1969) found that two of the 317 sibs, but none of the 198 parents, had clinically overt coeliac disease, ie, $0.4 \%(2 / 515)$ first degree relatives were affected. This contrasts with the higher incidence of affected first relatives which we found, namely, two out of 68 $(3.0 \%)$, but our sample is small and the difference is not statistically significant. Also McCrae found positive histories in one out of 902 second degree relatives and three out of 1,373 third degree relatives, whereas we found no history of clinical coeliac disease in these categories out of totals of 164 and 238 respectively. Again these differences are not statistically significant.

SMALL-INTESTINAL PATHOLOGY

The finding of a flat jejunal mucosa with the histo- 
logical features of subtotal villous atrophy in one of the parents in our series of 17 families is considered to be definitely pathological, for a change of this sort was not found in control series studied in Newcastle upon Tyne (Marks and Shuster, 1970) and in other geographical areas (Baker, Ignatius, Mathan, Vaish, and Chacko, 1962; Scott, Williams, and Clark, 1964; Banwell, Hutt, and Tunnicliffe, 1964; Salem and Truelove, 1965; England and O'Brien, 1966; Girdwood, Williams, McManus, Dellipiani, Delamore, and Kershaw, 1966; Stewart et al, 1967). Although we regarded this mother as not suffering from clinical coeliac disease it is probable that the mucosal abnormality was gluteninduced (Hindle and Creamer, 1965). The incidence $(2 / 29)$ of convoluted small-intestinal mucosa which we found in the parents is comparable to that $(4 / 48)$ in the Newcastle control series already mentioned, but this high incidence in our local population may itself be a reflection of occult coeliac disease (Marks and Shuster, 1970). Furthermore, we regarded one of the two parents with convoluted mucosa as showing clinical features of coeliac disease. If we consider both flat and convoluted mucosae to be abnormal then the incidence of these changes in the parents of our coeliac children is about $10 \%(3 / 29)$. This differs from the finding of MacDonald et al (1965) that there were no mucosal abnormalities in 12 parents of patients with coeliac disease although such changes were present in five of 33 siblings of the 17 propositi. It is interesting that Marks et al (1970) found a flat or convoluted mucosa in about $55 \%(6 / 11)$ of first degree relatives of patients with the coeliac syndrome associated with dermatitis herpetiformis. However, in all of these series the numbers are rather too small for definite conclusions to be drawn.

\section{GENETICS}

The absence of a simple Mendelian pattern of inheritance in clinical coeliac disease was noted by Carter et al (1959). Yet later workers (MacDonald et al, 1965), though conceding that different modes of inheritance were possible, still felt that their data suggested inheritance through a dominant gene of low penetrance and this interpretation continues to be quoted (Booth, 1970). The data arising from our investigation are not easy to explain by single gene inheritance, but are compatible with a multifactorial interpretation.

There are many diseases in which there is a definite familial tendency but in which the mode of inheritance is not Mendelian. It is becoming increasingly clear that in these conditions a different type of inheritance occurs, such as applies to continuously varying characters like stature. Liability to develop the disease is regarded as being under the control of a system of many genes situated at a number of loci and interacting with each other. Some genes promote liability to the disease, their alleles the reverse, just as some genes promote tall stature and their alleles short. Liability of an individual depends on the number of genes promoting it that he possesses. Were it possible to plot the number of individuals of a given liability in the population, a Gaussian or bell-shaped distribution curve would be produced just as in the case of stature. Towards one end of the distribution there occurs a threshold. Individuals who possess the appropriate loading of genes for susceptibility fall beyond this threshold and develop the disease. But just as stature can be influenced by differences in nutrition during growth, and some individuals who would genetically be slightly above the threshold of smallness are thrust by their environment into the small category, so also environment may affect the position of an individual relative to the threshold for coeliac disease. On this multifactorial model the respective contributions of inheritance and environment to liability to the disease may be measured (Falconer, 1965). The genetic contribution is known as the heritability.

There are several ways in which a multifactorial interpretation may be validated. Such an interpretation of coeliac disease is supported by McCrae's findings (1969), and particularly by his comparison of two small groups of coeliac children in whom the disease was supposed to have respectively a high (seven children) and a low (eight children) degree of genetic loading on the basis of early or late age of onset. A positive family history occurred more often in the relatives of early onset patients. On the basis of a multifactorial mode of inheritance, McCrae calculated the heritability (as defined by Falconer, 1965) of coeliac disease from its incidence in sibs to be $44 \% \pm 15$ and from its incidence in all relatives to be $45 \% \pm 13$.

Heritability of liability to coeliac disease as calculated from the findings in first degree relatives in the present series is $78 \% \pm 17$, which is higher than McCrae's estimate. Since there is no significant difference between our series and his in the number of affected relatives of a given degree, the two series may be combined to give a better estimate, namely, a heritability from first degree relatives of $46 \% \pm 10$ and from all degrees of relationship combined of $45 \% \pm 9$. Liability to clinical coeliac disease thus appears to be of moderate heritability.

Our findings show that the incidence of mucosal abnormality in relatives may differ from the incidence of clinical coeliac disease. Their incidences in the general population are also different (McCrae, 
1969; Marks and Shuster, 1970). Hence the heritabilities may differ. A reliable estimate of the heritability of the tendency to mucosal abnormality cannot be obtained from our figures alone, since the number of parents biopsied is small and estimates solely from first degree relatives are particularly liable to inflation. However, if it is assumed that the Newcastle population is similar in all relevant respects to that sampled by MacDonald et al (1965) and the two sets of data are combined, the heritability of the tendency to mucosal abnormality would be $16 \% \pm 21$, not significantly different from zero and below that for the clinical condition. Clearly it is desirable to extend the biopsy studies to a larger series of families, for confirmation of these figures would suggest a moderate genetic component in liability to mucosal atrophy with clinical coeliac disease, but a lesser, perhaps indeed negligible, genetic influence on the tendency to occult mucosal atrophy.

We thank Professor S. D. M. Court, Dr F. J. W. Miller, and Dr R. H. Jackson for permission to study their patients, and Mr J. A. Stewart and $\mathrm{Mr}$ J. R. MacLennan for technical assistance. The work was supported by MRC grants nos. 17901 and 17903.

Requests for reprints should be addressed to A.J.W.

\section{References}

Baker, S. J., Ignatius, M., Mathan, V. I., Vaish, S. K., and Chacko, C. C. (1962). Intestinal biopsy in tropical sprue. In Intestinal Biopsy, Ciba (Foundation Study Group, No. 14), edited by
G. E. W. Wolstenholme and M. P. Cameron, pp. 84-101. Churchill, London.

Banwell, J. G., Hutt, M. S. R., and Tunnicliffe, R. (1964). Observations on jejunal biopsy in Ugandan Africans. E. Afr. med. J., 41, 46-54.

Booth, C. C. (1970). Enterocyte in coeliac disease. Brit. med. J., 3, 725-731, and 4, 14-17.

Carter, C., Sheldon, W., and Walker, C. (1959). The inheritance of coeliac disease. Ann. hum. Genet., 23, 266-273.

England, N. W. J., and O'Brien, W. (1966). Appearances of the jejunal mucosa in acute tropical sprue in Singapore. Gut, 7, 128-139.

Falconer, D. S. (1965). The inheritance of liability to certain diseases estimated from the incidence among relatives. Ann. hum. Genet., 29, 51-76.

Girdwood, R. H., Williams, A. W., McManus, J. P. A., Dellipiani, A. W., Delamore, I. W., and Kershaw, P. W. (1966). Jejunal biopsy in patients with malabsorptive disease. Scot. med. J. 11, 343-355.

Hindle, W., and Creamer, B. (1965). Significance of a flat smallintestinal mucosa. Brit. med. J., 2, 455.

McCrae, W. M. (1969). Inheritance of coeliac disease. J. med. Genet., 6, 129-131.

MacDonald, W. C., Dobbins, W. O., III, and Rubin, C. E. (1965). Studies of the familial nature of celiac sprue during biopsy of the small intestine. New Engl. J. Med., 272, 448-456.

Marks, J., Birkett, D., Shuster, S., and Røberts, D. F. (1970). Small intestinal mucosal abnormalities in relatives of patients with dermitis herpetiformis. Gut, 11, 493-497.

Marks, J., and Shuster, S. (1970). Small intestinal mucosal abnormalities in various skin diseases-fact or fancy? Gut, 11, 281-291.

Salem, S. N., and Truelove, S. C. (1965). Small-intestinal and gastric abnormalities in ulcerative colitis. Brit. med. J., 1, 827-831.

Scott, G. B., Williams, M. J., and Clark, C. G. (1964). Comparison of jejunal mucosa in post-gastrectomy states, idiopathic steatorrhoea, and controls using the dissecting microscope and conventional histological methods. Gut, 5, 553-562.

Shuster, S., Watson, A. J., and Marks, J. (1967). Small intestine in psoriasis. Brit. med. J., 3, 458-460.

Stewart, J. S., Pollock, D. J., Hoffbrand, A. V., Mollin, D. L., and Booth, C. C. (1967). A study of proximal and distal intestinal structure and absorptive function in idiopathic steatorrhoea. Quart. J. Med., 36, 425-444.

Thaysen, T. E. H. (1935). Ten cases of idiopathic steatorrhoea. Quart J. Med., 4, 359-395.

Thompson, M. W. (1951). Heredity, maternal age and birth order in the etiology of celiac disease. Amer. J. hum. Genet., 3, 159. 166. 